\title{
Spondylolysis outcomes in adolescents after direct screw repair of the pars interarticularis
}

\author{
Clinical article
}

\author{
Laura A. Snyder, M.D., ${ }^{1}$ Harry Shufflebarger, M.D., ${ }^{2}$ Michael F. O'Brien, M.D., ${ }^{3}$ \\ Harjot Thind, B.A., ${ }^{1}$ Nicholas Theodore, M.D., ${ }^{1}$ and Udaya K. KaKarla, M.D. ${ }^{1}$
}

${ }^{1}$ Division of Neurological Surgery, Barrow Neurological Institute, St. Joseph's Hospital and Medical Center, Phoenix, Arizona; ${ }^{2}$ Center for Spinal Disorders and Department of Orthopedics, Miami Children's Hospital, Miami, Florida; and ${ }^{3}$ Baylor Scoliosis Center, Plano, Texas

\begin{abstract}
Object. Isthmic spondylolysis can significantly decrease functional abilities, especially in adolescent athletes. Although treatment can range from observation to surgery, direct screw placement through the fractured pars, or Buck's procedure, may be a more minimally invasive procedure than the more common pedicle screw-hook construct.

Methods. Review of surgical databases identified 16 consecutive patients treated with Buck's procedure from 2004 to 2010. Twelve patients were treated at Miami Children's Hospital and 4 at Barrow Neurological Institute. Demographics and clinical and radiographic outcomes were recorded and analyzed retrospectively.

Results. The 16 patients had a median age of 16 years, and 14 were 20 years or younger at the time of treatment. Symptoms included axial back pain in $100 \%$ of patients with concomitant radiculopathy in $38 \%$. Pars defects were bilateral in $81 \%$ and unilateral in $19 \%$ for a total of 29 pars defects treated using Buck's procedure. Autograft or allograft augmented with recombinant human bone morphogenetic protein as well as postoperative bracing was used in all cases. Postoperatively, symptoms resolved completely or partially in 15 patients (94\%). Of 29 pars defects, healing was observed in $26(89.6 \%)$ prior to 1 revision surgery, and an overall fusion rate of $97 \%$ was observed at last radiological follow-up. There were no implant failures. All 8 athletes in this group had returned to play at last follow-up.

Conclusions. Direct screw repair of the pars interarticularis defect as described in this series may provide a more minimally invasive treatment of adolescent patients with satisfactory clinical and radiological outcomes, including return to play of adolescent athletes.

(http://thejns.org/doi/abs/10.3171/2014.5.SPINE13772)
\end{abstract}

KEY WORDS • lumbar spine • spondylolysis • pars interarticularis

$\mathrm{S}$ PONDYLOLYSIS is a unilateral or bilateral defect in the pars interarticularis of the vertebra and is usually due to acute or repetitive microtrauma. The incidence of spondylolysis is estimated to be $6 \%-7 \%$ in the general adult population. ${ }^{1}$ The entity is not observed in nonambulatory infants, and the incidence at age 6 years is approximately $5 \%$. Hereditary predisposition and erect ambulation are thought to contribute to the development of the condition.

This type of defect most commonly occurs at L-5, as this is the vertebra subjected to the greatest static and dynamic stress associated with daily activities. ${ }^{12,19}$ As such, symptoms of spondylolysis are usually limited to low-back pain and occasionally radiculopathy, but these symptoms can be the cause of significantly reduced mo-

Abbreviation used in this paper: rhBMP-2 = recombinant human bone morphogenetic protein-2. bility and inactivity. Spondylolysis may progress to spondylolisthesis, which may result in substantial spinopelvic sagittal malalignment. ${ }^{12}$

As with other spinal pathologies, conservative treatment is the first-line treatment. Conservative treatment options for spondylolysis include reducing physical activity, undergoing physical therapy, and using thoracolumbar and/or sacral orthoses. If conservative treatment fails, surgery is indicated (either fixation and fusion or direct surgical repair). Pedicle screw fixation and fusion has been shown to result in loss of motion at the fused level and to potentially increase loading on adjacent segments. ${ }^{13,18}$ This can lead to symptomatic degeneration and can require additional surgery for these adjacent segments in up to $36 \%$ of patients. ${ }^{5,13}$ As such, direct repair is a better choice for treatment of patients with spondylolysis. It provides an internal fixation device that bridges the gap at the fracture site and maintains stability in all movements 


\section{A. Snyder et al.}

(flexion, extension, lateral bending, and axial rotation). Direct repair also allows for fracture repair without substantially altering the biomechanics of the intact spine.

There are several methods to accomplish direct pars repair: Buck's technique, Scott's technique, modified Scott's technique, and the screw-rod-hook technique. . $^{2,4}$ However, data on the usage and outcomes of these different surgical techniques are limited, especially in the adolescent population with spondylolysis. ${ }^{6}$ As athletics becomes increasing competitive and important to adolescent patients vying for college scholarships, it behooves the spine surgeon to evaluate spondylolysis fixation techniques. To this extent, we report our experience and outcomes with the use of Buck's procedure for surgical repair of spondylolysis in adolescent patients.

\section{Methods}

Data were collected prospectively on 16 consecutive adolescent patients with spondylolysis who underwent surgical treatment with Buck's procedure from 2004 to 2010. Of these 16 patients, 12 underwent surgery at Miami Children's Hospital and 4 underwent surgery at Barrow Neurological Institute. Prior to consideration of surgery, all 16 patients had complained of persistent back pain preventing them from their self-described normal activity. In all cases, patients were encouraged to trial conservative therapy, including at least 8 weeks in a lumbar brace and at least 8 weeks of physical therapy. Indications to progress to surgery included patient complaints of significant back pain preventing the patient from completion of conservative treatments, or patient complaints of back pain significantly impeding daily activity after completion of conservative therapy recommendations. Furthermore, patients were not considered as candidates for direct pars repair if they had disc degeneration or instability seen on lateral flexion-extension plain radiography. These patients were considered candidates for interbody placement and pedicle screw fusion instead of direct pars repair.

The operative technique used was as described by Buck. ${ }^{2}$ A midline incision and exposure was performed at the involved levels. The pars defect was exposed and decorticated to bleeding using a 3.2-mm drill bit. Screw entry points were created in the caudal portion of the lamina, $8-10 \mathrm{~mm}$ lateral to the bottom of the spinous process. The 3.2-mm drill bit was then used to drill across the defect angling $30^{\circ}$ away from the midline toward the pedicle, and 3.5- or 4.5-mm cannulated screws were placed across the pars defect via a K-wire under both direct visualization and lateral fluoroscopy. Either iliac crest autograft (12 patients) or allograft bone (4 patients) was packed around the lytic defect. Each pars defect was augmented with a $1.05-\mathrm{mg}$ dose of recombinant human bone morphogenetic protein-2 (rhBMP-2) in a US Food and Drug Administration off-label use. Postoperatively, all patients were placed in an orthosis for 8-12 weeks. We then completed a retrospective review of the data for demographic, clinical, and radiographic trends. The institutional review boards of St. Joseph's Hospital and Medical Center and Miami Children's Hospital approved this retrospective review.

\section{Results}

Sixteen adolescent patients with spondylolysis who were surgically treated using the Buck's procedure constitute the study group. Of these, 14 patients were 20 years of age or younger at the time of treatment. Additional patient demographics are described in Table 1. All 16 patients $(100 \%)$ presented with axial low-back pain, and 6 patients (38\%) had radiculopathy as well. In $75 \%$ of patients (12 of 16) conservative therapies of bracing and physical therapy had been attempted and failed. Eight patients had tried at least 8 weeks of physical therapy alone, and 4 patients had tried physical therapy for at least 8 weeks as well as bracing for at least 8 weeks. Twenty-five percent of patients were in significant pain and could not continue with a conservative treatment plan of bracing or physical therapy for more than 2 weeks and thus progressed to surgery. Most patients had bilateral pars defects, although 3 patients had unilateral pars defects (Table 2).

There were no intraoperative complications. Preoperative, intraoperative, and postoperative images obtained in 1 patient can be seen in Fig. 1. Two patients developed superficial wound infections and were successfully treated with oral antibiotics; these patients experienced full resolution of the infection. Two patients required revision surgeries: one for pseudarthrosis requiring repeat iliac crest grafting and the other for radiculopathy requiring screw removal. Given that the patient with pseudarthrosis ( 2 pars defects) required revision surgery and 1 patient had 2 pars defects, of which only 1 was noted to heal on follow-up CT, bony healing was seen in $26(89.6 \%)$ of 29 pars defects after the first surgery. Thus, 2 of 16 patients without bony healing were identified (12.5\%) after the first surgery. No implant failures were encountered (Table 3).

Postoperatively, patients were monitored for clinical and radiological examinations (Table 3). At the last radiological follow-up, the overall bony healing rate was $96.6 \%$ ( 28 of 29 pars defects in 15 [93.8\%] of 16 patients). The average time to last radiological follow-up was 13.19 months (range 12-24 months). At last clinical follow-up, preoperative symptoms had partially or completely resolved in $93.8 \%$ of patients. The average time to last clinical follow-up was 14.06 months (range 12-26 months). In addition, all 8 patients who identified as athletes had returned to play.

\section{Discussion}

Although conservative therapies are the gold standard in the initial treatment of spondylolysis, if these therapies fail, surgical treatment is indicated. Direct pars repair was first described in 1968 by Kimura, who grafted

TABLE 1: Patient demographics

\begin{tabular}{ll}
\hline \multicolumn{1}{c}{ Parameter } & Value \\
\hline no. of patients & 16 \\
no. of pars defects & 29 \\
median age in yrs (range) & $16(11-30)$ \\
\hline
\end{tabular}


Adolescent spondylolysis after repair of pars interarticularis

TABLE 2: Location of pars defects

\begin{tabular}{cc}
\hline Location & No. of Patients (\%) \\
\hline bilateral & $13(81)$ \\
L-3 & $1(6)$ \\
L-4 & $3(19)$ \\
L-5 & $9(56)$ \\
unilateral & $3(19)$ \\
L-3 & $1(6)$ \\
L-4 & $0(0)$ \\
L-5 & $2(13)$ \\
\hline
\end{tabular}

the defect alone. ${ }^{11}$ Buck was the first to describe stabilization of the defect by a direct pars screw in $1970 .{ }^{2}$ In 1984, Morscher described pars repair via hook-screw fixation, and in 1986, Nicol and Scott described his tension-band wiring technique. ${ }^{14,15}$ Often direct repair is preferred over pedicle screw fixation and fusion, because it can restore local normal spinal anatomy and maintain physiological spinal mobility at the level of the defect., ${ }^{43,18}$

Despite the use of direct pars screw repair, there has been little evidence or consensus on which specific direct repair technique provides the best outcomes. Deguchi et al. demonstrated that 4 techniques of direct screw repair (Buck's, Scott's, modified Scott's, and screw-rod-hook procedures) decreased the change in motion across a spondylolytic defect versus no surgical intervention. ${ }^{4} \mathrm{~A}$ retrospective study by Ivanic et al. involving 113 patients with spondylolysis who underwent direct repair with a
TABLE 3: Clinical and radiological follow-up*

\begin{tabular}{cc}
\hline Outcome & No. of Patients (\%) \\
\hline at last clinical follow-up & $14(88)$ \\
preop symptoms resolved & $1(6)$ \\
preop symptoms improved & $1(6)$ \\
persistent preop symptoms & \\
at last radiological follow-up & $15(93.8)$ \\
fusion of preop pars defect & $16(100)$ \\
hardware intact &
\end{tabular}

* The mean length of clinical follow-up was 14.06 months (range 1226 months), and the mean length of radiological follow-up was 13.19 months (range 12-24 months).

hook screw reported a pseudarthrosis rate of 13.3\%.7 A recent study by Shin et al. compared Buck's procedure to the screw-rod-hook procedure. ${ }^{17}$ They found that the rate of bony healing was higher in patients who underwent direct pars screw fixation (Buck's procedure) $(93.3 \%$ vs 78.3\%) and concluded that the direct pars screw fixation was superior to the pedicle screw with universal hook system, given that the former group of patients demonstrated decreased operative time, decreased blood loss, and decreased hospital stay as well as superior clinical outcomes..$^{17}$ A retrospective cohort study by Karatas et al. compared adolescent patients treated with direct pars repair procedure to patients treated with pedicle screwrod-hook constructs. ${ }^{9}$ Using the Macnab criteria, 8 of 9 patients treated with direct pars repair demonstrated "ex-
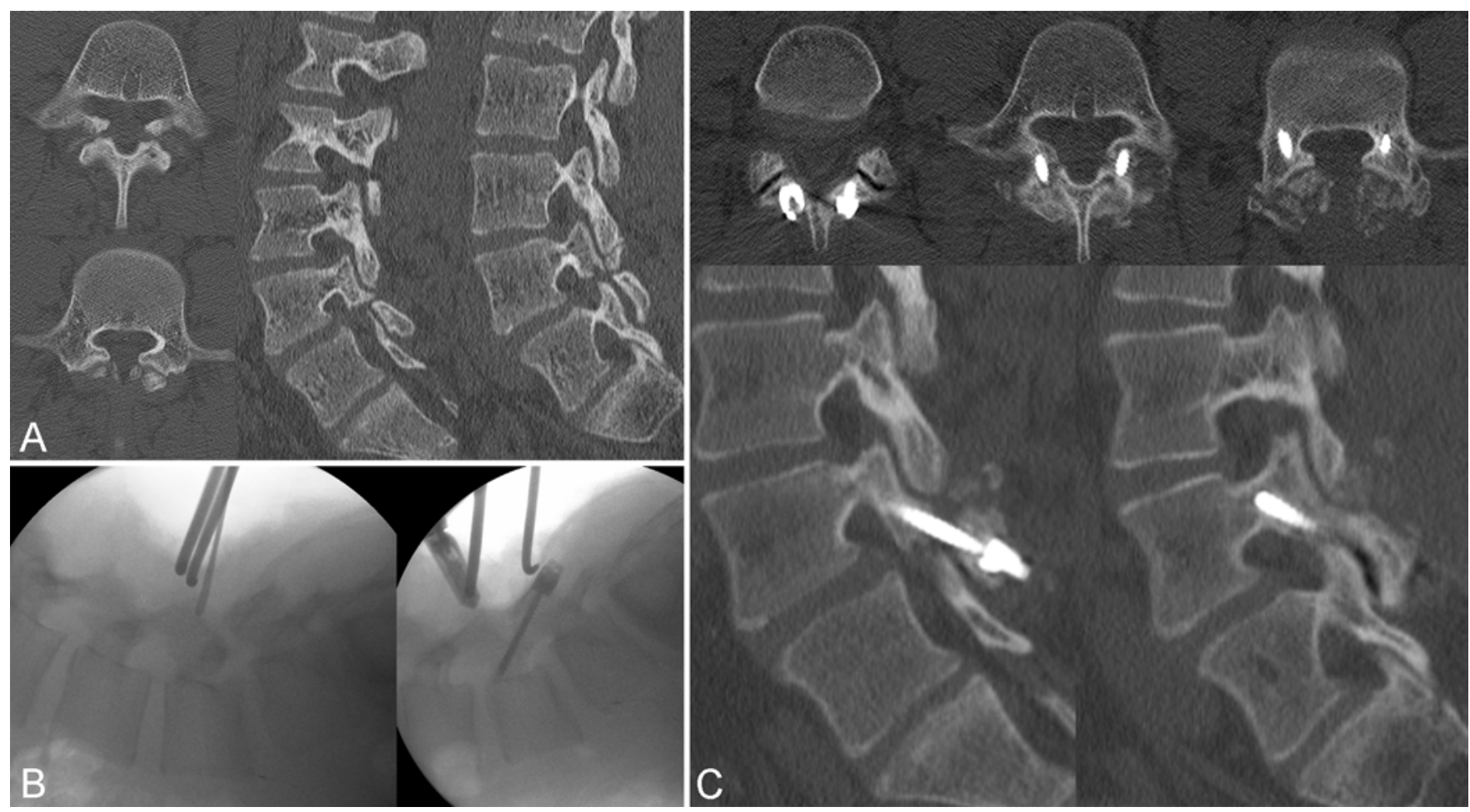

FIG. 1. Preoperative axial and sagittal CT images of the lumbar spine (A), intraoperative lateral radiographs of the lumbar spine (B), and postoperative axial and sagittal CT lumbar images (C) obtained in a 16-year-old football player with spondylolysis and direct pars screw repair. 


\section{A. Snyder et al.}

cellent" or "good" outcomes, while 6 of 7 patients demonstrated "excellent" or "good" outcomes when treated with pedicle screw-rod-hook constructs. Kim et al. retrospectively reviewed 50 pars defects in 25 patients who had symptomatic spondylolysis; all patients were younger than 30 years and had undergone direct pars repair using Buck's technique. ${ }^{10}$ Thirty-six of 50 pars defects demonstrated fusion, and 22 of 25 patients achieved an "excellent" or "good" outcome according to Kirkaldy-Willis criteria. Our results augment these conclusions and show that direct screw repair of the pars interarticularis, or Buck's procedure, can provide good clinical and radiological outcomes in adolescent patients.

As adolescent spondylolysis is rare and few cases progress to requiring surgery, this is a difficult patient population to study. It is difficult to determine which procedure is best for these patients and also whether they would benefit from surgery at all. Admittedly, this is a small series of only 16 patients. We do not know in this time period how many patients presented with similar symptoms as well as spondylolysis and experienced symptom resolution with conservative therapy alone. Furthermore, due to the retrospective nature of this study, there are some limitations in evaluating outcomes, and the group may have been subjected to management biases.

Whether the off-label use of rhBMP-2 in these cases was appropriate is debatable, because it may or may not provide an improved fusion construct with or without complications. In addition, its use comes at a significant financial cost. At the time these patients were treated, from 2004 to 2010, it was felt that due to the small area of bone contact from one portion of the pars contacting the other via the lag screw in the direct pars repair, the fusion would be significantly augmented by rhBMP-2. As iliac bone graft was not harvested in every case, the use of rhBMP-2 was also seen as a way to augment fusion without the associated complications of iliac bone grafting. No complications in these patients related to the use of rhBMP-2 have been identified at this point, neither clinically nor radiologically. On follow-up CT and radiography, no foraminal overgrowth was appreciated. However, as more recent literature has questioned whether fusion actually is improved with rhBMP-2, especially in young patients, some surgeons would prefer not to use it at this time.

It must be noted that patients with disc or facet disruption are likely not good candidates for this procedure. ${ }^{3,16}$ These patients may be better served by pedicle screw fixation and fusion with interbody graft. However, spine surgeons should be aware that direct pars repair by Buck's technique can provide good outcomes in the adolescent patient population with isthmic spondylolysis alone and significant back pain, and the procedure should be considered a good option after failure of conservative techniques.

\section{Conclusions}

It has been postulated previously that because Buck's technique may prevent abnormal motion of the fractured pars without compromising the normal motion of the spine at that level, patients may have improved clinical outcomes over other fixation procedures. This paper describes 16 adolescent patients with spondylolysis who had good outcomes after Buck's technique for direct pars repair. Although surgery should never be the first-line treatment for adolescent spondylolysis, Buck's technique of direct pars repair should be considered in adolescent athletes with persistent significant symptoms after a trial of conservative therapy, as it may improve their quality of life and decrease their time to return to play.

\section{Disclosure}

The authors report no conflict of interest concerning the materials or methods used in this study or the findings specified in this paper.

Author contributions to the study and manuscript preparation include the following. Conception and design: Kakarla, Shufflebarger, O'Brien. Acquisition of data: Kakarla, Shufflebarger, O'Brien. Analysis and interpretation of data: Kakarla, Shufflebarger, O'Brien, Theodore. Drafting the article: Kakarla, Snyder, Thind. Critically revising the article: all authors. Reviewed submitted version of manuscript: all authors. Approved the final version of the manuscript on behalf of all authors: Kakarla. Statistical analysis: Kakarla, Snyder, Thind. Administrative/technical/material support: Kakarla, Snyder, Thind. Study supervision: Kakarla, Snyder, Shufflebarger, O'Brien, Theodore.

\section{References}

1. Beutler WJ, Fredrickson BE, Murtland A, Sweeney CA, Grant WD, Baker D: The natural history of spondylolysis and spondylolisthesis: 45-year follow-up evaluation. Spine (Phila Pa 1976) 28:1027-1035, 2003

2. Buck JE: Direct repair of the defect in spondylolisthesis. Preliminary report. J Bone Joint Surg Br 52:432-437, 1970

3. Debnath UK, Freeman BJ, Gregory P, de la Harpe D, Kerslake RW, Webb JK: Clinical outcome and return to sport after the surgical treatment of spondylolysis in young athletes. J Bone Joint Surg Br 85:244-249, 2003

4. Deguchi M, Rapoff AJ, Zdeblick TA: Biomechanical comparison of spondylolysis fixation techniques. Spine (Phila Pa 1976) 24:328-333, 1999

5. Ghiselli G, Wang JC, Bhatia NN, Hsu WK, Dawson EG: Adjacent segment degeneration in the lumbar spine. J Bone Joint Surg Am 86-A:1497-1503, 2004

6. Hensinger RN: Spondylolysis and spondylolisthesis in children and adolescents. J Bone Joint Surg Am 71:1098-1107, 1989

7. Ivanic GM, Pink TP, Achatz W, Ward JC, Homann NC, May M: Direct stabilization of lumbar spondylolysis with a hook screw: mean 11-year follow-up period for 113 patients. Spine (Phila Pa 1976) 28:255-259, 2003

8. Johnson GV, Thompson AG: The Scott wiring technique for direct repair of lumbar spondylolysis. J Bone Joint Surg Br 74:426-430, 1992

9. Karatas AF, Dede O, Atanda AA, Holmes L Jr, Rogers K, Gabos P, et al: Comparison of direct pars repair techniques of spondylolysis in pediatric and adolescent patients: pars compression screw versus pedicle screw-rod-hook. J Spinal Disord Tech [epub ahead of print], 2012

10. Kim YT, Lee H, Lee CS, Lee DH, Hwang CJ, Ahn TS: Direct repair of the pars interarticularis defect in spondylolysis. J Spinal Disord Tech [epub ahead of print], 2012

11. Kimura M: [My method of filing the lesion with spongy bone in spondylolysis and spondylolisthesis.] Seikei Geka 19:285296, 1968 (Jpn)

12. Leone A, Cianfoni A, Cerase A, Magarelli N, Bonomo L: 


\section{Adolescent spondylolysis after repair of pars interarticularis}

Lumbar spondylolysis: a review. Skeletal Radiol 40:683-700, 2011

13. Mihara H, Onari K, Cheng BC, David SM, Zdeblick TA: The biomechanical effects of spondylolysis and its treatment. Spine (Phila Pa 1976) 28:235-238, 2003

14. Morscher E, Gerber B, Fasel J: Surgical treatment of spondylolisthesis by bone grafting and direct stabilization of spondylolysis by means of a hook screw. Arch Orthop Trauma Surg 103:175-178, 1984

15. Nicol RO, Scott JH: Lytic spondylolysis. Repair by wiring. Spine (Phila Pa 1976) 11:1027-1030, 1986

16. Rajasekaran S, Subbiah M, Shetty AP: Direct repair of lumbar spondylolysis by Buck's technique. Indian J Orthop 45:136140,2011

17. Shin MH, Ryu KS, Rathi NK, Park CK: Direct pars repair surgery using two different surgical methods: pedicle screw with universal hook system and direct pars screw fixation in symptomatic lumbar spondylosis patients. J Korean Neurosurg Soc 51:14-19, 2012
18. Ulibarri JA, Anderson PA, Escarcega T, Mann D, Noonan KJ: Biomechanical and clinical evaluation of a novel technique for surgical repair of spondylolysis in adolescents. Spine (Phila Pa 1976) 31:2067-2072, 2006

19. Wiltse LL, Widell EH Jr, Jackson DW: Fatigue fracture: the basic lesion is inthmic spondylolisthesis. J Bone Joint Surg Am 57:17-22, 1975

Manuscript submitted August 15, 2013.

Accepted May 20, 2014.

Please include this information when citing this paper: published online June 20, 2014; DOI: 10.3171/2014.5.SPINE13772.

Address correspondence to: Udaya K. Kakarla, M.D., c/o Neuroscience Publications, Barrow Neurological Institute, St. Joseph's Hospital and Medical Center, 350 W. Thomas Rd., Phoenix, AZ 85013.email: neuropub@dignityhealth.org. 